\title{
Sulphur dioxide as a volcanic ash proxy during the April-May 2010 eruption of Eyjafjallajökull Volcano, Iceland
}

\author{
H. E. Thomas ${ }^{1}$ and A. J. Prata ${ }^{2}$ \\ ${ }^{1}$ Department of Geological Engineering and Sciences, Michigan Technological University, Houghton, MI, USA \\ ${ }^{2}$ Nordic Institute for Air Research (NILU), Kjeller, Norway \\ Received: 18 February 2011 - Published in Atmos. Chem. Phys. Discuss.: 7 March 2011 \\ Revised: 20 June 2011 - Accepted: 29 June 2011 - Published: 18 July 2011
}

\begin{abstract}
The volcanic ash cloud from the eruption of Eyjafjallajökull volcano in April and May 2010 resulted in unprecedented disruption to air traffic in Western Europe causing significant financial losses and highlighting the importance of efficient volcanic cloud monitoring. The feasibility of using $\mathrm{SO}_{2}$ as a tracer for the ash released during the eruption is investigated here through comparison of ash retrievals from the Spinning Enhanced Visible and Infrared Imager (SEVIRI) with $\mathrm{SO}_{2}$ measurements from a number of infrared and ultraviolet satellite-based sensors. Results demonstrate that the eruption can be divided into an initial ashrich phase, a lower intensity middle phase and a final phase where considerably greater quantities both ash and $\mathrm{SO}_{2}$ were released. Comparisons of ash- $\mathrm{SO}_{2}$ dispersion indicate that despite frequent collocation of the two species, there are a number of instances throughout the eruption where separation is observed. This separation occurs vertically due to the more rapid settling rate of ash compared to $\mathrm{SO}_{2}$, horizontally through wind shear and temporally through volcanological controls on eruption style. The potential for the two species to be dispersed independently has consequences in terms of aircraft hazard mitigation and highlights the importance of monitoring both species concurrently.
\end{abstract}

\section{Introduction}

The Eyjafjallajökull volcano, Iceland $\left(63.63^{\circ} \mathrm{N}\right.$, $19.6215^{\circ} \mathrm{W} ; 1666 \mathrm{~m}$ a.s.1.) erupted explosively on 14 April 2010 and continued to emit ash and gas until 24 May. Despite the relatively modest size of the eruption, the prevailing wind conditions to the south-east resulted in

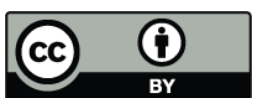

Correspondence to: $\mathrm{H}$. E. Thomas (hethomas@mtu.edu) the eruption having a considerable impact upon aviation in Europe. The closure of the majority of European airspace from 17-19 April alone led to an estimated loss of \$1.7 billion to the aviation industry (IATA, 2010). One of the most significant consequences of the eruption was the change in flight safety policy from zero tolerance to the introduction of ash concentration thresholds (CAA, 2010). The International Civil Aviation Organization (ICAO) have now defined areas of low $\left(<2 \times 10^{-3} \mathrm{~g} \mathrm{~m}^{-3}\right)$, medium $\left(2-4 \times 10^{-3} \mathrm{~g} \mathrm{~m}^{-3}\right)$ and high $\left(>4 \times 10^{-3} \mathrm{~g} \mathrm{~m}^{-3}\right)$ ash concentration to determine where flight is allowable (low), allowable under certain specific conditions (medium) or prohibited (high) (ICAO, 2010).

At least 94 confirmed incidents were reported from 1953 2009 (Guffanti et al., 2010), where the most serious have only narrowly avoided catastrophe due to engine flame outs. With the current rapid rate of air traffic growth (ESCAP, 2005) there is the potential for many more such incidents and it is the responsibility of the Volcanic Ash Advisory Centers (VAACs) to provide advisories to the aviation industry through the effective modelling and monitoring of eruption clouds. Throughout the Eyjafjallajökull eruption, the London VAAC at the UK Met Office was responsible for producing model predictions for the location of the ash cloud. Following the introduction of a quantitative ash threshold, predictions of ash concentration were also reported in order to advise the aviation authorities throughout the six-week eruption period. However, reliance on models alone is problematic due to the nature of volcanological and meteorological conditions which can cause rapid and unexpected changes in ash distribution. Satellite remote sensing provides means by which model results can be validated in near real-time and subsequently used to improve the accuracy of outputs (e.g. Stohl et al., 2011) thereby allowing volcanic cloud predictions with greater certainty. 
Table 1. Properties of the instruments used in this study.

\begin{tabular}{lllll}
\hline Instrument & Platform & $\begin{array}{l}\text { Overpass Time } \\
\text { (local equatorial ascending) }\end{array}$ & $\begin{array}{l}\text { Field of view } \\
\text { (or swath width) }\end{array}$ & Nadir Spatial Resolution \\
\hline AIRS & Aqua & $13: 30$ & $1650 \mathrm{~km}$ & $14 \mathrm{~km}$ \\
GOME-2 & MetOp-A & $09: 30$ & $1920 \mathrm{~km}$ & $80 \times 40 \mathrm{~km}$ \\
IASI & MetOp-A & $09: 30$ & $2112 \mathrm{~km}$ & $12 \mathrm{~km}$ \\
SEVIRI & MSG & 15 min sampling time & Full disk, centred: $0^{\circ} \mathrm{N} 0^{\circ} \mathrm{E}$ & $10 \mathrm{~km}$ \\
OMI & Aura & $13: 45$ & $2600 \mathrm{~km}$ & $13 \times 24 \mathrm{~km}$ \\
\hline
\end{tabular}

Explosive magmatic eruptions typically emit both ash and sulphur dioxide $\left(\mathrm{SO}_{2}\right)$ concurrently. As $\mathrm{SO}_{2}$ is generally easier to detect than ash with space-based instruments (Eckhardt et al., 2008), it is frequently used as a proxy for ash (Carn et al., 2009). Furthermore, $\mathrm{SO}_{2}$ clouds may also be associated with very fine ash particles which are difficult to detect using remote sensing methods, but could still pose a hazard to aircraft (Carn et al., 2009). While volcanic ash primarily affects aircraft engines, rapid conversion of $\mathrm{SO}_{2}$ in the atmosphere to sulphuric acid aerosols (sulphate) can cause an increase in corrosion rates of aircraft compressor blades (Swadzba et al., 1996). The presence of sulphate aerosols at cruising altitudes can also result in rapid crazing of acrylic windows and a number of cases of airframe damage have been attributed to the eruptions of El Chichón, Mexico in 1982 and Pinatubo in 1991 (Bernard and Rose, 1990; Casadevall et al., 1996).

Although the two species are usually released concurrently, separation may occur through wind shear and particle settling (Prata and Kerkmann, 2007). Furthermore, the success of volcanic ash retrievals using infrared algorithms are highly dependent on water and ice content of the cloud, which can mask the ash signal in high quantities (Pavolonis et al., 2006). As the Eyjafjallajökull eruption was initially subglacial, this is likely to play a significant role in ash cloud detection due to the elevated water vapour in the cloud.

In this study the validity of using $\mathrm{SO}_{2}$ as a tracer for volcanic ash is assessed for the case of the Eyjafjallajökull eruption by comparing retrievals of ash concentration from the geosynchronous Meteosat Second Generation (MSG) Spinning Enhanced Visible and Infrared Imager (SEVIRI), with additional retrievals of sulphur dioxide from a range of satellite-based sensors on polar orbiting platforms. The Global Ozone Monitoring Instrument 2 (GOME-2) and the Infrared Atmospheric Sounding Interferometer (IASI) onboard the Eumetsat MetOp-A platform, the Ozone Monitoring Instrument (OMI) on the NASA Aura satellite and the Atmospheric Infrared Radiation Sounder (AIRS) on the NASA Aqua platform are all capable of detecting volcanic $\mathrm{SO}_{2}$ with varying spatial, spectral and temporal resolutions (Table 1). The use of a number of sensors allows for a greater wealth of information about the plume altitude and distribution to be determined than through using just one sensor alone (Thomas et al., 2011). The Cloud-Aerosol Lidar with Orthogonal Polarisation (CALIOP) spaceborne lidar, on board the CALIPSO platform has also been used to provide information about aerosol altitude and vertical distribution of ash and aerosol particles. Also utilised are the European Centre for Medium-Range Weather Forecasts (ECMWF) interim reanalysis data, for comparison of cloud transportation with local wind fields. These data contain the $u$ and $v$ wind velocity components at a $1^{\circ}$ resolution from sea level up to $0.1 \mathrm{hPa}$ at six hourly intervals (Berrisford et al., 2009).

Satellite observations are compared to the prediction issued by the London VAAC using the operational dispersion model, NAME III (Numerical Atmospheric - dispersion Modelling Environment) (Jones et al., 2007). The model is a Lagrangian dispersal model, uses inputs of meteorology from either the Met Office Numerical Weather Prediction (NWP) Unified Model (UM) or ECMWF (Jones et al., 2007). During the eruption, particle size was predefined with a six-bin distribution $(0.1-100 \mu \mathrm{m}$; peak at 10 $30 \mu \mathrm{m})$, ash density fixed at $2300 \mathrm{~g} \mathrm{~m}^{-3}$, a constant ash eruption rate of $1 \times 10^{9} \mathrm{~g} \mathrm{~s}^{-1}$ and plume height based on three hourly observations provided by the Icelandic Met Office were used (Mylne, 2010). The model allows for gravitational settling and wet and dry deposition processes, although no attempt is made to model the plume rise dynamics (Mylne, 2010). Predictions were released on a six-hourly basis for the north Atlantic region and are available online from http://www.metoffice.gov.uk/aviation/vaac/. Throughout the event, data from satellites were used to provide information on ash dispersion and therefore assist in alteration of model parameters.

\section{Methodology}

\subsection{Ash retrievals}

The retrieval of volcanic ash for the SEVIRI instrument is based on the brightness temperature difference (BTD) between channels $9(10.8 \mu \mathrm{m})$ and $10(12 \mu \mathrm{m})$ (Prata, 1989a, b), which is negative for silicate ash. The refractive indices of andesitic ash particles, consistent with the findings of Sigmundsson et al.,(2010), were defined as a function of wavelength (Pollack et al., 1973) were interpolated and convolved with the SEVIRI response functions and input into a Mie 
scattering code using a range of particle sizes and wavelengths. A discrete ordinates model (DOM) (Stamnes and Swanson, 1981) and a look up table for the range of top of atmosphere (TOA) brightness temperatures for each of the two channels is generated. These values are then compared with the atmospherically corrected (Yu et al., 2002) satellite data to derive the optical depth and ash properties, which are used to compute the total ash mass of each pixel (Wen and Rose, 1994; Prata and Grant, 2001). The retrieval scheme was applied to all images acquired between April 14 and May 25 to generate ash maps for every $15 \mathrm{~min}$ interval during the eruption period, resulting in a total of 3936 images. The total mass was also calculated for each scene by summing up the mass loadings and multiplying by the total area of affected pixels. The detection limit of the SEVIRI ash retrieval has been determined as approximately $0.5 \mathrm{~g} \mathrm{~m}^{-2}$, amounting to a sensitivity of approximately $0.001 \mathrm{~g} \mathrm{~m}^{-3}$ for a cloud with $500 \mathrm{~m}$ vertical thickness. The accuracy of total ash mass loading calculated from SEVIRI are around $\pm 50 \%$ (Prata and Prata, 2010).

The retrieval of ash is compounded by the presence of water vapour and ice in the cloud which can mask the signal of volcanic ash due to the positive BTD of these species (Wen and Rose, 1994; Prata and Grant, 2001). Furthermore, retrievals at night time over cloud free land often return a slightly negative BTD which adds noise to the date, making the exact delimitation of the ash cloud more difficult (Prata and Grant, 2001).

\section{$2.2 \mathrm{SO}_{2}$ retrievals}

The retrieval of the partial column $\mathrm{SO}_{2}$ from AIRS uses the channels around the $7.3 \mu \mathrm{m}$ absorption band, using the method of Prata and Bernardo, (2007) and is described briefly here. Firstly, a correlation method is used to identify the correct band to use for the retrieval, which is then compared with a library band shape. In the second stage, the $\mathrm{SO}_{2}$ amount is retrieved in $2 \mathrm{~km}$ thick parallel layers with an optimal estimation technique (Rodgers, 2000), which are then summed yield the partial column $\mathrm{SO}_{2}$. The retrieval is most limited when the thermal contrast between the $\mathrm{SO}_{2}$ cloud and the surface beneath it is small, when there is a large amount of water vapour in the atmosphere or if the retrieval band becomes saturated due to high concentrations of absorbing species which reduces the sensitivity of the band to changes in $\mathrm{SO}_{2}$ concentration (Prata et al., 2003; Prata and Bernardo, 2007). Errors range from approximately \pm 3 Dobson Units (DU) up to $\pm 6 \mathrm{DU}$, depending on the amount of water vapour interference, which tends to restrict the retrieval to clouds residing above the water-rich troposphere (ca. $3 \mathrm{~km}$ ) with the detection limit at approximately 5 DU (Thomas et al., 2011). Band saturation is not seen in the AIRS retrievals for Eyjafjallajökull, which only occurs when the cloud is optically thick making the spectra appear flat, although water vapour interference is a problem in many of the images. These lim- itations must be borne in mind when making comparisons with estimates from other sensors (e.g. OMI and GOME-2).

Retrieval of $\mathrm{SO}_{2}$ from IASI is described by Clarisse et al. (2008). Like AIRS, IASI is sensitive to $\mathrm{SO}_{2}$ in the middleto upper-troposphere and lower stratosphere, with sensitivity limited by the water vapour content of the atmosphere and clouds. In principle, the better spectral resolution and slightly better signal-to-noise of IASI compared to AIRS provides better $\mathrm{SO}_{2}$ retrievals, and Clerbaux et al., (2009) estimate a sensitivity down to $2 \mathrm{DU}$, but so far a thorough validation, error analysis and inter comparison of retrievals has not been undertaken.

The ultraviolet (UV) sensors OMI and GOME-2 measure the total backscattered solar irradiance from the Earth's surface and the $\mathrm{SO}_{2}$ total column is computed using the BeerBouguer-Lambert law. Absorption due to $\mathrm{SO}_{2}$ is differentiated from that of ozone by using measurements at multiple wavelengths (Kerr, 1980; Krueger, 1983; Krueger et al., 1995). OMI $\mathrm{SO}_{2}$ data are derived using the linear fit algorithm of Yang et al. (2007) and are retrieved as the OMSO2 product from http://mirador.gsfc.nasa.gov/. Error in estimates of the a priori cloud altitude can result in errors of up to $20 \%$ or $15 \%$ respectively, depending on whether the altitude is over-or under- estimated (Yang et al., 2007). Further error due to the nonlinear effect can result in underestimation of total $\mathrm{SO}_{2}$ column by $20 \%$ (for a $100 \mathrm{DU}$ column) up to $70 \%$ where $\mathrm{SO}_{2}$ loadings are high (400 DU) (Yang et al., 2007). GOME-2 products are computed using a differential optical absorption spectroscopy (DOAS) algorithm (Eisinger and Burrows, 1998) and are provided online at http://sacs.aeronomie.be/. Heue et al., (2011) estimate retrieval of $\mathrm{SO}_{2}$ vertical column density accuracy at approximately 1.3 DU for Eyjafjallajökull measurements which provides a minimum error of around $25 \%$ for the data presented here. As these UV sensors measure the total column $\mathrm{SO}_{2}$, using radiance which has been scattered by the entire atmosphere, $\mathrm{SO}_{2}$ at low altitude can also be detected with an detection limits as low as 0.6 DU (Brinksma et al., 2003; Rix et al., 2008). Although the retrievals include terms to account for thin or broken clouds, molecular scattering, gas absorption, aerosols and Rotational Raman Scattering although presence of dense meteorological cloud or significant aerosol can mask the volcanic signal (Yang et al., 2007, 2009).

\subsection{Spaceborne lidar}

$\mathrm{SO}_{2}$ data from all four sensors were analysed for the period 14 April-24 May and images containing $\mathrm{SO}_{2}$ were compared with the nearest time-coincident ash retrieval from SEVIRI along with information from the CALIOP lidar where available (browse images v. 3.01 acquired from http://www.calipso.larc.nasa.gov/). CALIOP measures atmospheric backscatter profiles at 532 and $1064 \mathrm{~nm}$ up to $40 \mathrm{~km}$ altitude as well as a perpendicular backscatter component at $532 \mathrm{~nm}$ (Vaughan et al., 2004). Returned products 
available in the browse images include the total attenuated backscatter at $532 \mathrm{~nm}$, the depolarization ratio and the attenuated colour ratio $(1064 / 534 \mathrm{~nm})$. Small particles return lower values of attenuated colour ratio due to the lower amounts of backscatter at $1064 \mathrm{~nm}$. The amount and ratio of backscatter from the lidar measurements can provide information in to the vertical extent and location of volcanic ash and sulphate aerosols as well as providing some details regarding particle size and type (Thomason and Pitts, 2008).

\section{Observations and discussion}

\subsection{Eruption chronology}

After a number of weeks of heightened seismic activity and a fissure eruption at Fimmvörðuháls lasting approximately three weeks, the summit eruption of Eyjafjallajökull began on 14 April, sending ash clouds to more than $8 \mathrm{~km}$ a.s.l. (BGS, 2010). From 19 April until early May, activity continued with a lower intensity with plume altitudes reaching an average height of $4 \mathrm{~km}$ (Smithsonian Institution, 2010). In early May, the plume was reported to be darker and wider than during the past three weeks showing a rapid increase in ash discharge rate with both lava-producing and explosive phases (Icelandic Met Office, 2010; Smithsonian Institution, 2010). On May 4, the explosive activity at Eyjafjallajökull was seen to gain intensity, with observations estimating the plume altitude at $6 \mathrm{~km}$ a.s.l. (Hjaltadóttir et al., 2010). The volcano continued to emit ash and gas up until 24 May when the eruption ended. These different phases of the eruption can be clearly distinguished using satellite data. Figure 1 shows the total ash tonnage as measured by SEVIRI for each image throughout the eruption period, along with the OMI and AIRS $\mathrm{SO}_{2}$ tonnages for overpasses which captured the entire cloud region (so that results were not biased by overpasses where only part of the plume was imaged). The first phase is dominated by ash with very little $\mathrm{SO}_{2}$ detected by either AIRS or OMI which is consistent with the sub-glacial nature of the eruption. The middle phase shows little in the way of ash or $\mathrm{SO}_{2}$ detected by the satellite based sensors, indicating that the explosions at this time were much less ash -rich and likely dominated by water vapour, along with a small amount of low altitude $\mathrm{SO}_{2}$, as detected by OMI. The final phase is indicative of a magmatic eruption releasing both $\mathrm{SO}_{2}$ and ash in two distinct phases, peaking on May 9 and May 15.

\subsection{5 and 16 April}

During the first phase, $\mathrm{SO}_{2}$ clouds were difficult to distinguish in the AIRS and IASI imagery, due to their low altitude and concentration, although some $\mathrm{SO}_{2}$ was detected by the UV sensors on a number of days. Figure 2 shows the near-coincident SEVIRI ash retrievals with the OMI and GOME-2 $\mathrm{SO}_{2}$ retrievals on 15 and 16 April. The images

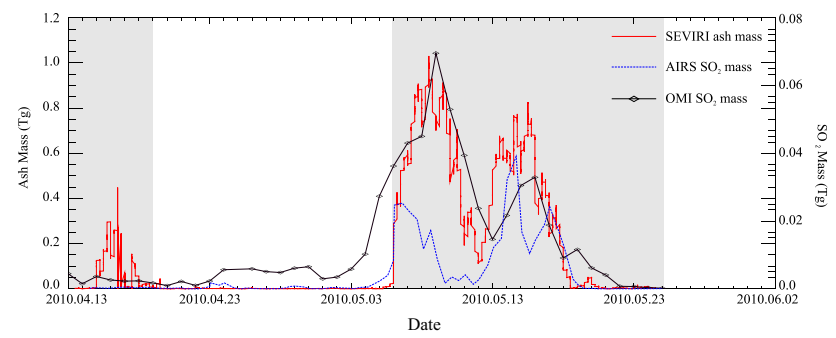

Fig. 1. Total tonnage of ash retrieved at $15 \mathrm{~min}$ intervals from the MSG SEVIRI instrument along with the total $\mathrm{SO}_{2}$ mass detected by the OMI and AIRS instruments for the entire eruption period. The shaded regions define the three different stages of the eruptive activity.

show some spatial disparity between regions of $\mathrm{SO}_{2}$ and ash as measured by the instruments. On 15 April, the $\mathrm{SO}_{2}$ cloud extends further to the east than the majority of the ash and the relative locations of ash and $\mathrm{SO}_{2}$ show that there is little gas associated with the area of densest ash. Conversely, the most concentrated area of $\mathrm{SO}_{2}$ to the east does not appear to have high ash concentrations associated with it.

The images from GOME-2 and SEVIRI on the April 16 show a general collocation of the ash and gas, although the GOME-2 imagery does detect a noteworthy $\mathrm{SO}_{2}$ cloud over Finland $\left(\sim 62^{\circ} \mathrm{N}, 2^{\circ} \mathrm{E}\right)$ that is larger than the corresponding region of ash. By observing the clouds' evolution over time, this $\mathrm{SO}_{2}$ was originally associated with the ash cloud visible in the SEVIRI image at 12:00 UTC (Fig. 2a), and was erupted at approximately $08: 30$ on 15 April. It is possible that during the 24 hours of transportation in the atmosphere the majority of the large ash particles will have settled out, leaving just $\mathrm{SO}_{2}$ and fine ash in suspension. Due to the sub-glacial nature of the eruption in the early explosive phase, rapid ash fall-out is possible as the high water and ice content of the cloud would facilitate the removal of ash by gravity (Rose et al., 1995). Comparison with the VAAC model prediction shows that both the ash and $\mathrm{SO}_{2}$ are within the region originally forecasted to contain ash. However, these images also demonstrate that the region delineated by the VAAC model is much larger than the area of volcanic species detected by any of the sensors. Whether or not ash was present in most of this region remains unknown, as it is possible ash particles below the detection limit of the spaceborne instruments were present and just not detected.

\subsection{May}

Retrievals from 4 May demonstrate the advantage of using $\mathrm{SO}_{2}$ retrievals in order to locate the cloud where ash retrievals may fail (Fig. 3). At this time, the eruption was beginning to re-intensify, although the SEVIRI ash retrievals for this day do not indicate the presence of a sustained ash plume. The ash is visible in the MODIS visible imagery 


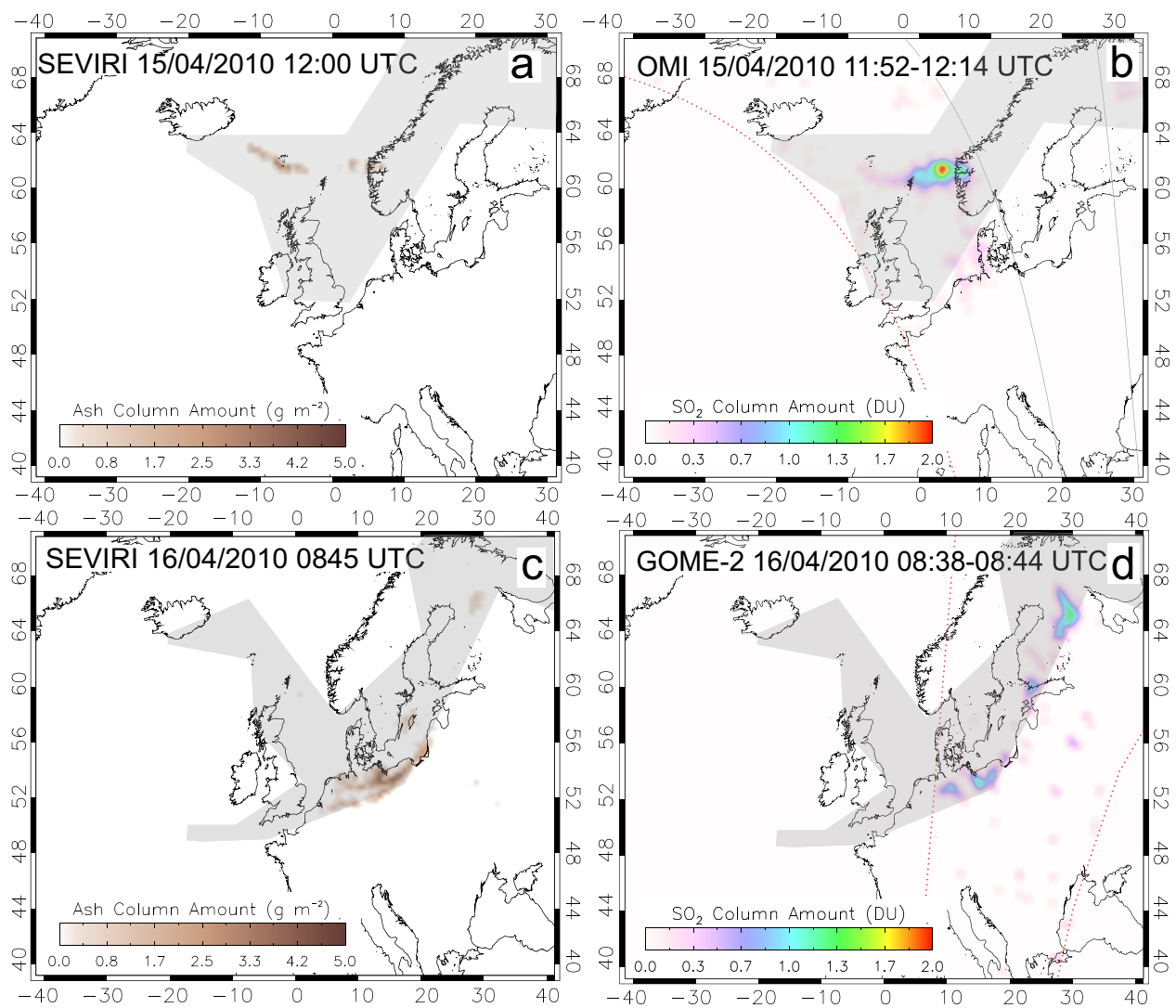

Fig. 2. Near-coincident retrieval of ash from SEVIRI with OMI SO 2 on April 15 (a and b) and with GOME-2 $\mathrm{SO}_{2}$ data on $16 \mathrm{April}$ (c) and d). Red dashed lines indicate the swath edge of the polar orbiting instruments and grey lines indicate the limit of the OMI row anomaly, between which no useable data are recorded. The grey shaded region indicates the area predicted to contain ash as forecast by the London VAAC at the time of the eruption.

(Fig. 3c), and can also be identified subjectively in timeseries of SEVIRI brightness temperature imagery. However, subjective interpretation cannot be automated for rapid detection and does not permit numerical estimates of concentration, which have now become important in terms of defining regions of aircraft hazard. The $\mathrm{SO}_{2}$ cloud in this case is evidently imaged by the two UV sensors and is therefore assumed to be at low altitude ( $<6 \mathrm{~km}$ a.s.l.) over the United Kingdom $\left(\sim 51-64^{\circ} \mathrm{N}, 2-10^{\circ} \mathrm{W}\right)$ as it remains undetected by both AIRS and IASI. The OMI aerosol index (AI) is a measure of absorption by aerosols at $360 \mathrm{~nm}$, including volcanic ash (Torres et al., 2007). In this case the OMI AI data is only able to detect the densest region of ash close to the vent and like the IR sensors, is unable to distinguish the majority of the cloud. The low plume altitude and cloudy meteorological conditions, as indicated by the MODIS visible image, are likely to have limited the ability of the ash retrieval algorithms to effectively identify the ash cloud. The spatial comparison with the output from the London VAAC model for this day shows that the region of $\mathrm{SO}_{2}$ actually extends further to the east of the designated no-fly zone which may have implications for aircraft operating in this region.

\subsection{May}

On 7 May, the $\mathrm{SO}_{2}$ retrieval from the morning overpass of IASI compared with the SEVIRI ash indicates that the two species are well collocated (Fig. 4). However, the GOME-2 $\mathrm{SO}_{2}$ imagery indicates a segment of $\mathrm{SO}_{2}$ which is further to the north and west than the ash. This separation is observed to remain at 14:30 UTC when the AIRS and OMI overpasses occurred (Fig. 5, a-c). The separated part of the cloud is thought to be below about $6 \mathrm{~km}$ a.s.l., as very little $\mathrm{SO}_{2}$ is detected by IASI and AIRS. The CALIOP Lidar track, coincident with the AIRS and OMI afternoon overpasses on the 7 May also intersected the volcanic cloud and can be used to infer the process causing the ash and gas separation (Fig. 5). The data indicate that the portion of the cloud through which the lidar track passes, may actually be distributed over several altitude levels, between approximately 3 and $9 \mathrm{~km}$. A second feature to the north, also likely to be associated with volcanic aerosol forms a thinner layer around $5 \mathrm{~km}$ a.s.l.This layer shows low attenuated colour ratio (ACR) and depolarisation measurements, but strong backscatter at $532 \mathrm{~nm}$ which is more likely to indicate the presence of smaller sulphate 


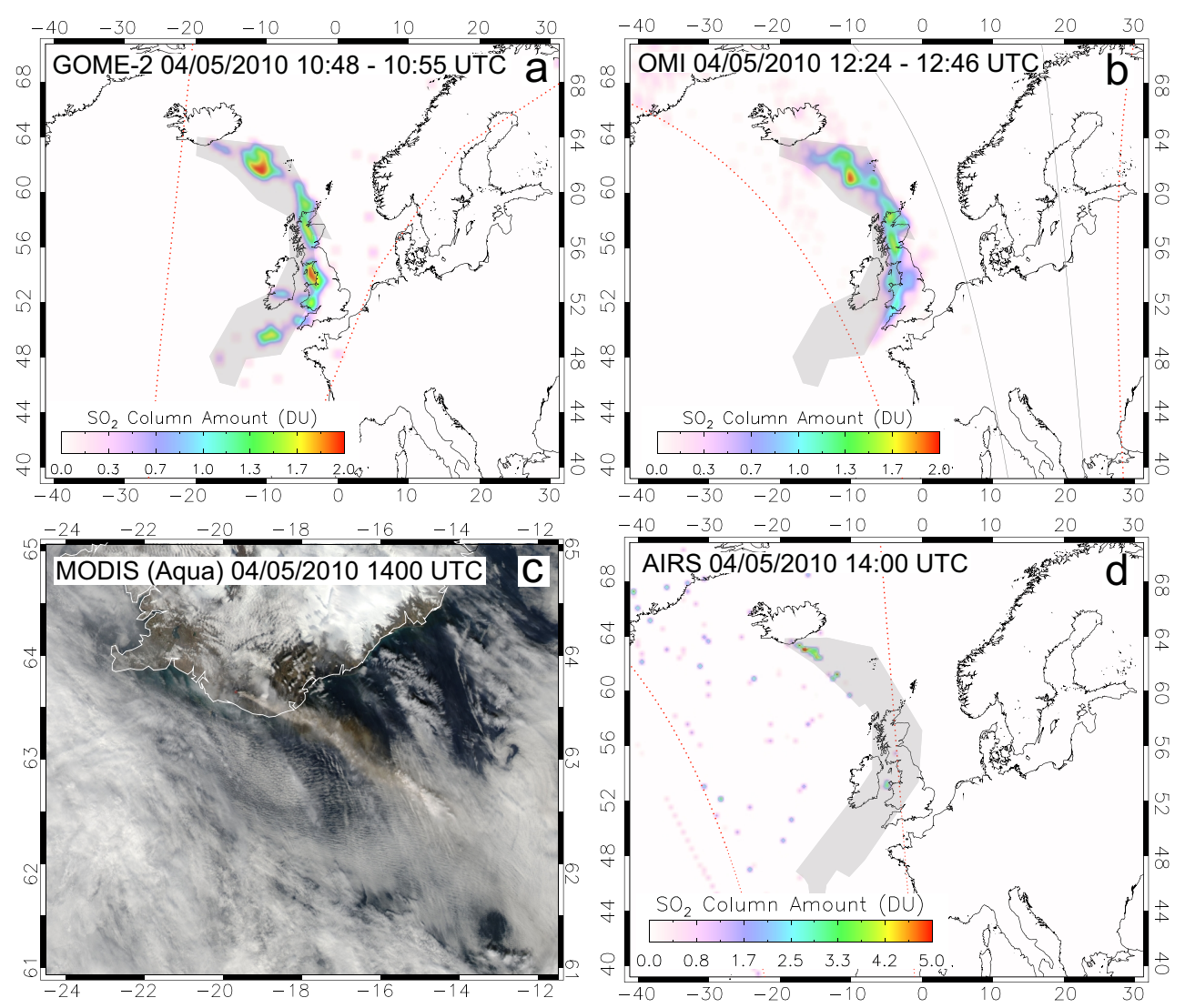

Fig. 3. $\mathrm{SO}_{2}$ retrievals from GOME-2, OMI and AIRS on 4 May 2010 (a, b and d) and the visible image from the MODIS instrument on the Aqua platform showing the ash plume as it leaves the volcano. As before, red dashed lines indicate the swath edge of the polar orbiting instruments and grey lines indicate the limit of the OMI row anomaly, between which no useable data are recorded. The grey shaded region indicates the area predicted to contain ash as forecast by the London VAAC at the time of the eruption.

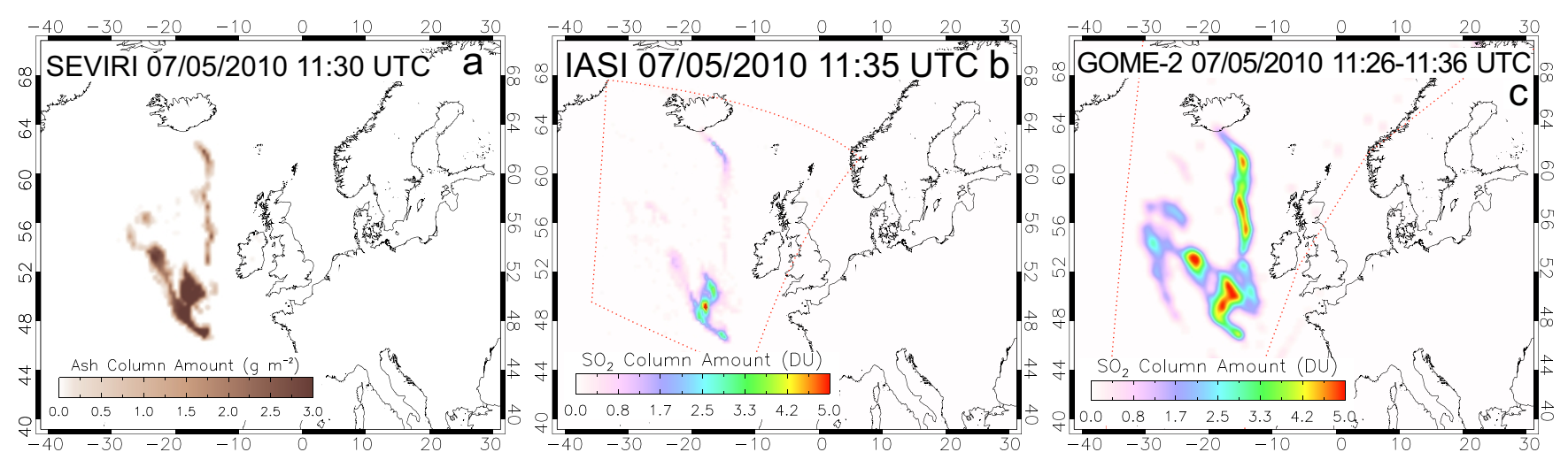

Fig. 4. Ash retrieval for 7 May 2010 from MSG-SEVIRI with the near-coincident retrievals of $\mathrm{SO}_{2}$ from the IASI and GOME-2 instruments. As before, red dashed lines indicate the swath edge of the polar orbiting instruments (the image limit in the case of IASI).

aerosol as opposed to ash. It therefore seems likely that this layer represents the eastern edge of the separated $\mathrm{SO}_{2}$ cloud. In order to confirm this hypothesis, the European Centre Medium-Range Weather Forecasts (ECMWF) reanalysis wind field data are also evaluated (Fig. 6). These data demon- strate that although wind direction is fairly constant around $165^{\circ}$ over all altitudes, the wind speed between $600 \mathrm{hPa}$ and $400 \mathrm{hPa}$ (ca. 4-6 km a.s.l.) is higher than that immediately above and below, which is likely to be causing the observed shearing to the north-west. 

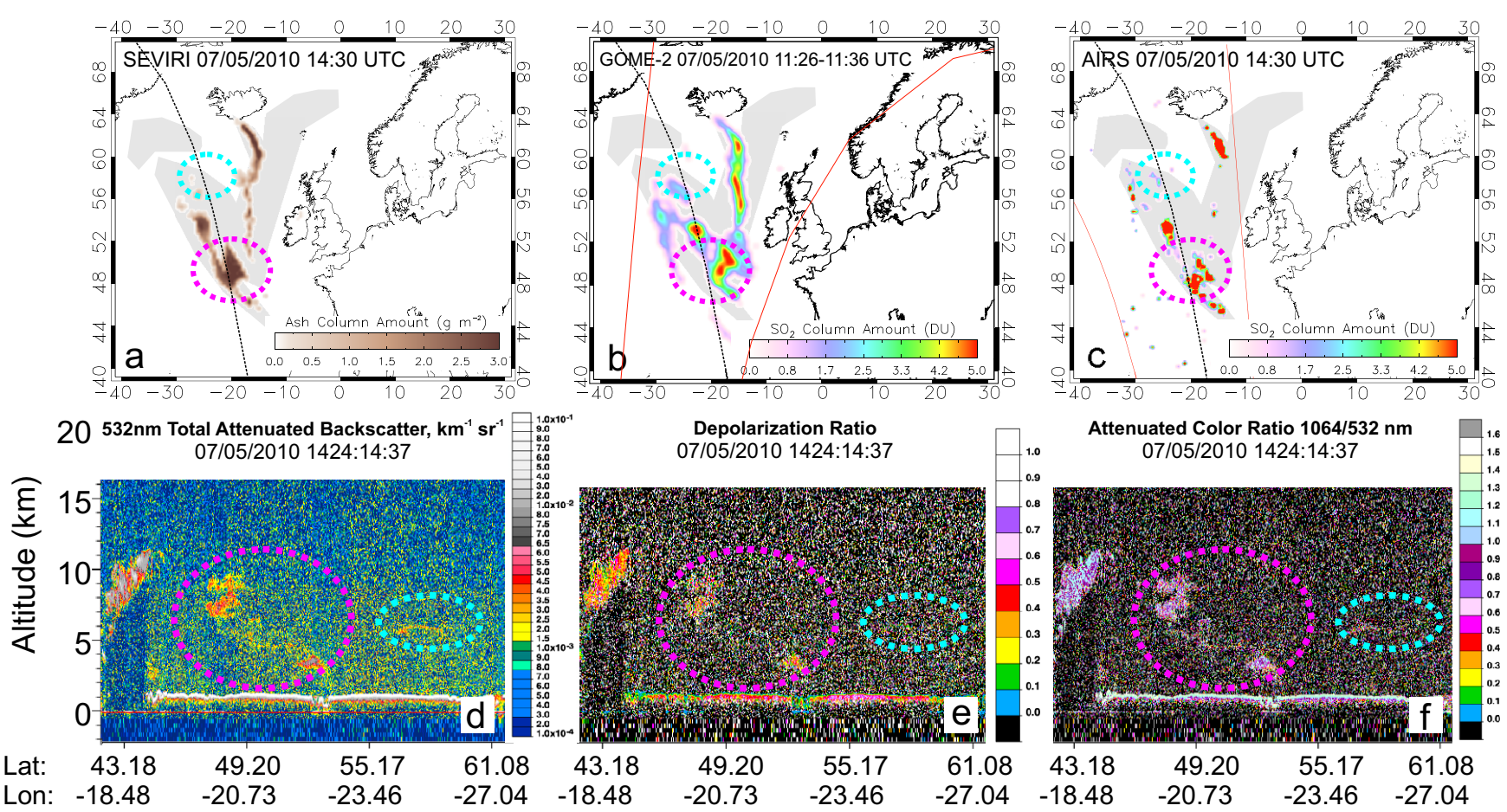

Fig. 5. Retrievals of ash and $\mathrm{SO}_{2}$ for 7 May from SEVIRI, AIRS and OMI (a-c) as well as the coincident data from the CALIOP spaceborne lidar (d-f). The pink and turquoise circles indicate where the lidar track crosses the cloud and the associated features visible in the lidar imagery. The dashed black line defines the ground track of the lidar. As before the red dashed lines indicate the swath edge of the polar orbiting instruments and the grey lines delimit the OMI row anomaly, between which no useable data are acquired.
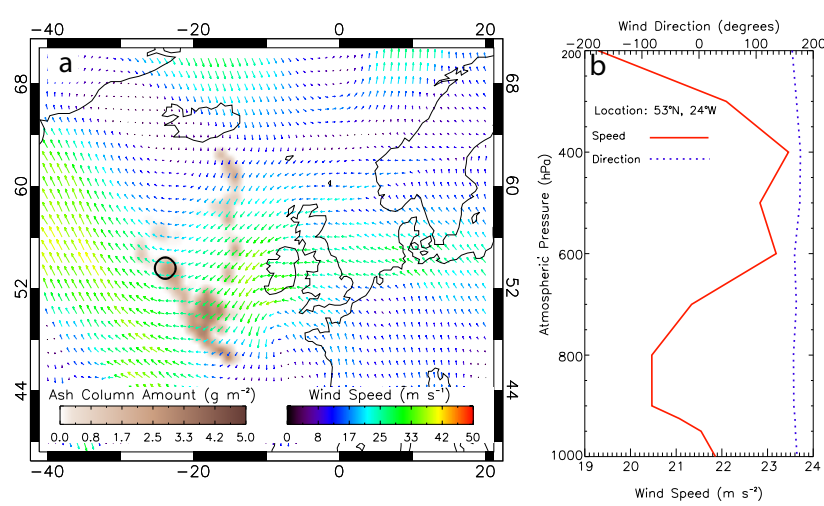

Fig. 6. (a) ECMWF reanalysis data for 12:00 UTC on 7 May at $500 \mathrm{hPa}$ with the coincidental SEVIRI ash retrieval underlain. (b) Vertical profile of wind speed and direction taken from the ECMWF wind data at $53^{\circ} \mathrm{N}, 24^{\circ} \mathrm{W}$, location indicated by the black circle in (a).

\subsection{May}

During the late afternoon of 13 May the cloud shows a change in plume direction from predominantly easterly and northerly to south-easterly. Figure 7 shows the ash retrieval from SEVIRI from 12:30 UTC on the 13 May un- til 03:30 UTC on May 14 which demonstrates this change in direction. The coincident OMI, IASI and AIRS $\mathrm{SO}_{2}$ retrievals for this period are also shown. The satellite data indicates that both species are changing direction, although the AIRS and IASI images suggest that the concentration of $\mathrm{SO}_{2}$ moving south exceeds that going north, whereas ash concentrations are approximately equal. Figure 8 shows the ECMWF wind fields at approximately $10 \mathrm{~km}$ and $3 \mathrm{~km}$ a.s.1. at 18:00 UTC on 13 May. The southerly component of the wind at $10 \mathrm{~km}$ is much stronger than at $3 \mathrm{~km}$ and the opposite is true for the winds which are moving the cloud to the north-west. It therefore seems likely that the southward moving ash and gas are at a higher altitude than the cloud moving north.

\section{Conclusions}

The ash and gas cloud released during the eruption of Eyjafjallajökull was imaged throughout the period of 15 April24 May by a number of satellite based sensors. Ash retrievals from the MSG SEVIRI instrument at $15 \mathrm{~min}$ intervals and $\mathrm{SO}_{2}$ measurements from OMI, GOME-2, IASI and AIRS are all useful in detecting and locating the cloud which shows highly variable dispersion over the nearly six week period. This work has demonstrated that through 

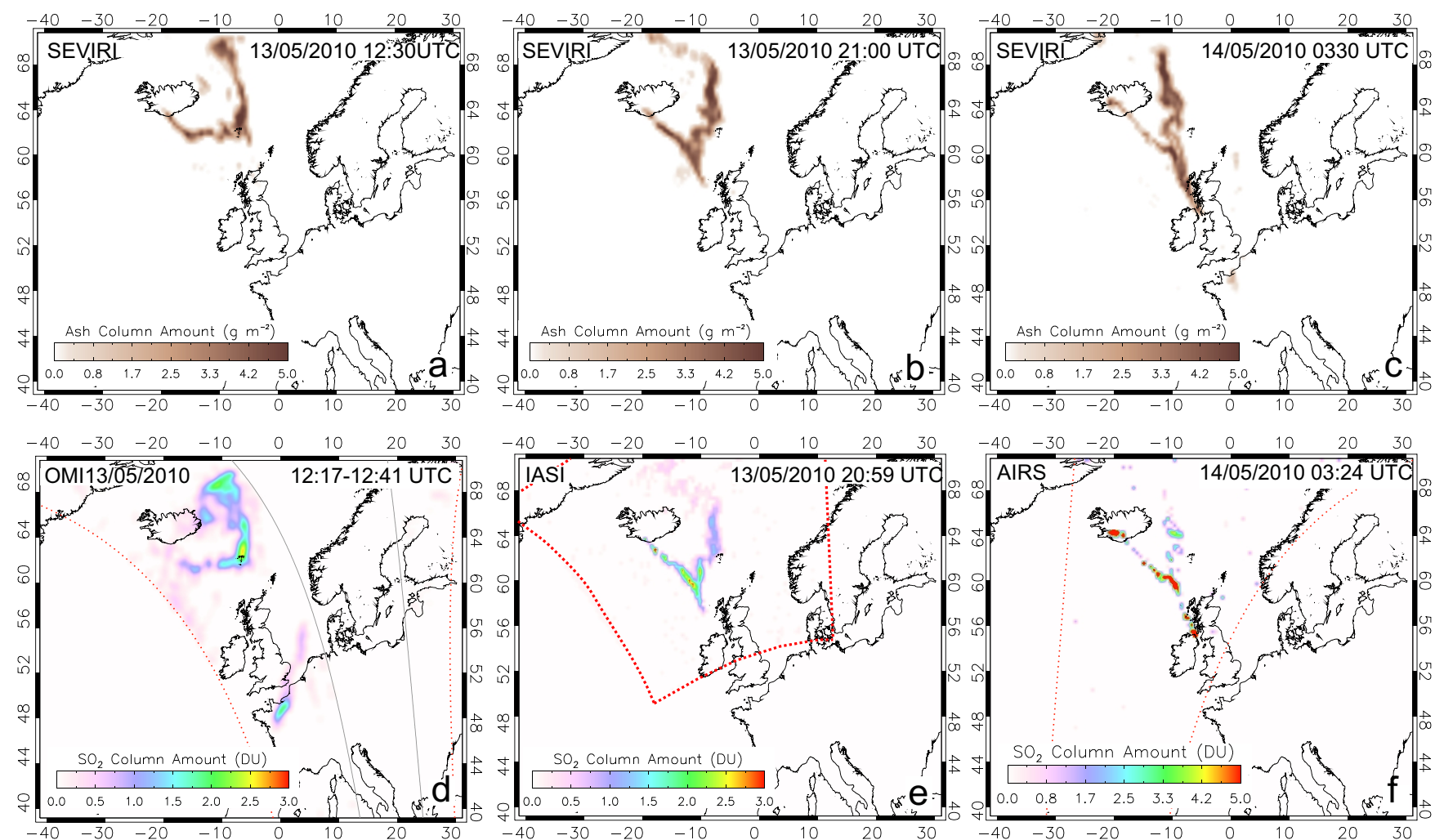

Fig. 7. Ash (a-c) from SEVIRI and $\mathrm{SO}_{2}$ retrievals (d-e) for the latter half of 13 May and the early morning on 14 May. During this time period the volcanic cloud is seen to make a dramatic change in direction. As before, red dashed lines indicate the edge of swath (or image limits in the case of IASI) of the polar orbiting instruments and the grey lines delimit the OMI row anomaly between which there are no useable data.

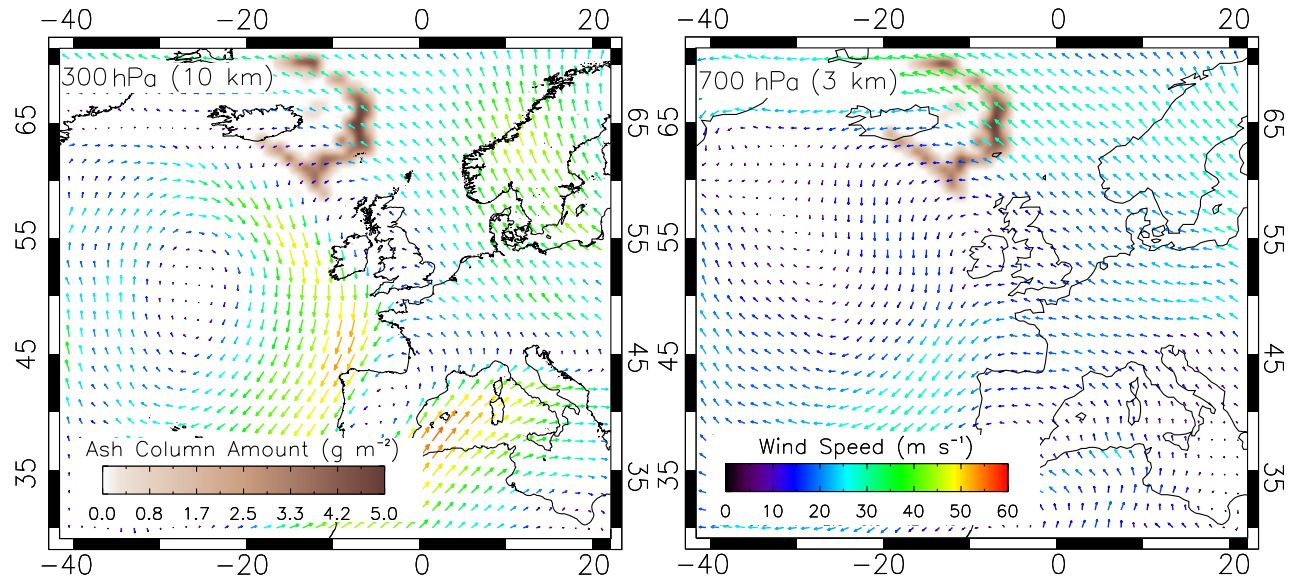

Fig. 8. ECMWF windfield data for $13 \mathrm{May}$ at 18:00 UTC for the $300 \mathrm{hPa}$ and $700 \mathrm{hPa}$ levels (approximately $10 \mathrm{~km}$ and $3 \mathrm{~km}$ respectively) with the coincident SEVIRI ash retrieval underlain. The windfield data shows a stronger southern component at high altitude with a stronger south-easterly windspeed at lower altitude.

comparison of coincident measurements of ash and $\mathrm{SO}_{2}$, the validity of using $\mathrm{SO}_{2}$ as a tracer for the motion of ash in this instance can be evaluated. Satellite data indicates that for majority of the eruption the gas and ash were collocated, although there are some instances where the two species do vary spatially. Separation due to the differential residence times of ash and $\mathrm{SO}_{2}$ in the atmosphere results in the $\mathrm{SO}_{2}$ cloud travelling further distances than the ash. This 
has important consequences for the aviation industry as it is likely some of the finest ash particles are remnant in the cloud. Separation due to wind shear has also been seen to occur on some days. Shearing can affect one species more than the other when vertical separation has taken place either due to the initial eruption style or through differential rates of particle settling. Finally, one instance where the $\mathrm{SO}_{2}$ retrievals from the UV sensors detect a considerable gas cloud while no ash is observed. In this instance, the existing meteorology may have significantly limited the effectiveness of the ash retrieval algorithm so that any ash present was not detected. Alternatively, the cloud may have been predominantly composed of $\mathrm{SO}_{2}$ as indicated by the UV sensors, which would affect the level of perceived risk to aircraft.

In conclusion, the monitoring of both species is important during volcanic eruption episodes in order to provide the most accurate representation of volcanic clouds in both time and space. The use of the polar orbiting UV sensors, although lacking the temporal frequency of SEVIRI, allow for the more sensitive detection of $\mathrm{SO}_{2}$ which can, as has been shown here, detect the volcanic cloud where the ash algorithm cannot. The presence of $\mathrm{SO}_{2}$, while not confirming the co-existence of ash, could be associated with fine ash particles and could itself pose a hazard. The range of datasets provided by spaceborne remote sensing also may also be used to validate dispersion models used in the mitigation of aircraft hazards.

Acknowledgements. The authors acknowledge Eumetsat for financial support for this research. We also thank L. Clarisse (ULB) for provision of IASI data, S. Carn (MTU) OMI data and discussion of CALIPSO data, S. Eckhardt (NILU) for acquiring the 3D wind field data from ECMWF and S. Murray (UoB) for proof reading and P. Webley (UAF), M. Watson (UoB) and J. Shannon (MTU) for their helpful comments.

Edited by: C. Bay Hasager

\section{References}

Bernard, A. and Rose, W.: The injection of sulfuric acid aerosols in the stratosphere by the El Chichón volcano and its related hazards to the international air traffic, Nat. Hazards, 3, 59-67, doi:10.1007/bf00144974, 1990.

Berrisford, P. D., Dee, K., Fielding, M., Fuentes, P., Kallberg, S., Kobayashi, S., and Uppala, S.: The ERA-Interim archive, Report Series. 1, European Centre for Medium-Range Weather Forecasts, Shinfield Park, Reading UK, 2009.

BGS: Changing eruption styles at Eyjafjallajökull in Iceland, available online at: http://www.bgs.ac.uk/research/highlights/ changingEruptionStyles.html, last access: 17 February, 2010.

Brinksma, E. J., Boersma, K. F., and Levelt, P. F.: OMI Validation Requirements Document, KNMI, 2003.

CAA: Rationale for the removal of the current volcanic ash buffer zone, v.1.1, Civil Aviation Authority, 2010.

Carn, S., Krueger, A., Krotkov, N., Yang, K., and Evans, K.: Tracking volcanic sulfur dioxide clouds for aviation hazard mitiga- tion, Nat. Hazards, 51, 325-343, doi:10.1007/s11069-008-92284, 2009.

Casadevall, T. J., Delos Reyes, P. J., and Schneider, D. J.: The 1991 Pinatubo eruptions and their effects on aircraft operations, in: Fire and mud: eruptions and lahars of Mount Pinatubo, Philippines, edited by: Newhall, C. G., and Punongbayan, R. S., University of Washington Press, Seattle/London, 1071-1088, 1996.

Clarisse, L., Coheur, P. F., Prata, A. J., Hurtmans, D., Razavi, A., Phulpin, T., Hadji-Lazaro, J., and Clerbaux, C.: Tracking and quantifying volcanic $\mathrm{SO}_{2}$ with IASI, the September 2007 eruption at Jebel at Tair, Atmos. Chem. Phys., 8, 7723-7734, doi:10.5194/acp-8-7723-2008, 2008.

Clerbaux, C., Boynard, A., Clarisse, L., George, M., Hadji-Lazaro, J., Herbin, H., Hurtmans, D., Pommier, M., Razavi, A., Turquety, S., Wespes, C., and Coheur, P. F.: Monitoring of atmospheric composition using the thermal infrared IASI/MetOp sounder, Atmos. Chem. Phys., 9, 6041-6054, doi:10.5194/acp-9-6041-2009, 2009.

Eckhardt, S., Prata, A. J., Seibert, P., Stebel, K., and Stohl, A.: Estimation of the vertical profile of sulfur dioxide injection into the atmosphere by a volcanic eruption using satellite column measurements and inverse transport modeling, Atmos. Chem. Phys., 8, 3881-3897, doi:10.5194/acp-8-3881-2008, 2008.

Eisinger, M., and Burrows, J. P.: Tropospheric sulfur dioxide observed by the ERS-2 GOME instrument, Geophys. Res. Lett., 25, 4177-4180, doi:10.1029/1998g1900128, 1998.

ESCAP: Review of developments in transport in Asia and the Pacific 2005, Economic and Social Commission for Asia and the Pacific, 2005.

Guffanti, M., Casadevall, T. J., and Budding, K.: Encounters of Aircraft with Volcanic Ash Clouds: A Compilation of Known Incidents, 1953-2009, USGS, 2010.

Heue, K. P., Brenninkmeijer, C. A. M., Baker, A. K., RautheSchöch, A., Walter, D., Wagner, T., Hörmann, C., Sihler, H., Dix, B., Frieß, U., Platt, U., Martinsson, B. G., van Velthoven, P. F. J., Zahn, A., and Ebinghaus, R.: $\mathrm{SO}_{2}$ and $\mathrm{BrO}$ observation in the plume of the Eyjafjallajökull volcano 2010: CARIBIC and GOME-2 retrievals, Atmos. Chem. Phys., 11, 2973-2989, doi:10.5194/acp-11-2973-2011, 2011.

Hjaltadóttir, S., Sigmundsson, F., Oddsson, B., Hreinsdóttir, S., Roberts, M. J., and Sveinbjörnsson, H.: Eruption in Eyjafjallajökull Status Report: 15:00 GMT, 04 May 2010., Icelandic Meteorological Office and Institute of Earth Sciences, University of Iceland, 2010.

IATA: Press Release: Volcano Crisis Cost Airlines \$1.7 Billion in Revenue - IATA Urges Measures to Mitigate Impact: http:// www.iata.org/pressroom/pr/Pages/2010-04-21-01.aspx, last access: 2 February, 2010.

ICAO: EUR DOC 019 -Volcnic Ash Contingency Plan - EUR and NAT regions (2nd Edition), International Civil Aviation Authority, 2010.

Icelandic Met Office: Update on activity in Eyjafjallajökull: http:// en.vedur.is/earthquakes-and-volcanism/articles/nr/1884, last access: 3 February, 2010.

Jones, A., Thomson, D., Hort, M., and Devenish, B.: The U.K. Met Office's Next-Generation Atmospheric Dispersion Model, NAME III, in: Air Pollution Modeling and Its Application XVII, edited by: Borrego, C., and Norman, A.-L., Springer US, 580589, 2007. 
Kerr, J. B., McElroy, C. T., and Olafson, R. A.: Measurements of Ozone with the Brewer Ozone Spectrophotometer, Proc. Int. Ozone Symp., 74-79, 1980.

Krueger, A. J.: Sighting of El Chichon Sulfur Dioxide Clouds with the Nimbus 7 Total Ozone Mapping Spectrometer, Science, 220, 1377-1379, doi:10.1126/science.220.4604.1377, 1983.

Krueger, A. J., Walter, L. S., Bhartia, P. K., Schnetzler, C. C., Krotkov, N. A., Sprod, I., and Bluth, G. J. S.: Volcanic sulfur dioxide measurements from the total ozone mapping spectrometer instruments, J. Geophys. Res., 100, 14057-14076, doi:10.1029/95jd01222, 1995.

Mylne, K.: Use of EPS for Volcanic Ash Forecasting. , ECMWF Forecast Products Users' Meeting, Shinfield Park, Reading, 911 June 2010, 2010.

Pavolonis, M. J., Feltz, W. F., Heidinger, A. K., and Gallina, G. M.: A Daytime Complement to the Reverse Absorption Technique for Improved Automated Detection of Volcanic Ash, J. Atmos. Ocean. Technol., 23, 1422-1444, doi:10.1175/JTECH1926.1, 2006.

Pollack, J. B., Toon, O. B., and Khare, B. N.: Optical properties of some terrestrial rocks and glasses, Icarus, 19, 372-389, doi:10.1016/0019-1035(73)90115-2, 1973.

Prata, A. J.: Infrared radiative transfer calculations for volcanic ash clouds, Geophys. Res. Lett., 16, 1293-1296, doi:10.1029/GL016i011p01293, 1989a.

Prata, A. J.: Observations of volcanic ash clouds in the 10-12 $\mu \mathrm{m}$ window using AVHRR/2 data, Int. J. Remote Sens., 10, 751-761, 1989b.

Prata, A. J. and Bernardo, C.: Retrieval of volcanic $\mathrm{SO}_{2}$ column abundance from Atmospheric Infrared Sounder data, J. Geophys. Res., 112, D20204, doi:10.1029/2006jd007955, 2007.

Prata, A. J. and Grant, I. F.: Retrieval of microphysical and morphological properties of volcanic ash plumes from satellite data: Application to Mt Ruapehu, New Zealand, Q. J. Roy. Meteorol. Soc., 127, 2153-2179, doi:10.1002/qj.49712757615, 2001.

Prata, A. J. and Kerkmann, J.: Simultaneous retrieval of volcanic ash and $\mathrm{SO}_{2}$ using MSG-SEVIRI measurements, Geophys. Res. Lett., 34, L05813, doi:10.1029/2006g1028691, 2007.

Prata, A. J., Rose, W. I., Self, S., and O'Brien, D. M.: Global, longterm sulphur dioxide measurements from TOVS data: A new tool for studying explosive volcanism and climate, In Volcanism and the Earth's Atmosphere (ed. Robock and Oppenheimer), Geophys. Monograph. 139, 75-92, 2003.

Prata, F. and Prata, A.: Eyjafjallajokull volcanic ash concentrations determined from CALIOP and SEVIRI measurements (Invited), AGU Fall Meeting Abstracts, 2010.

Rix, M., Valks, P., Hao, N., Erbertseder, T., and van Geffe, J.: Monitoring of volcanic $\mathrm{SO}_{2}$ emissions using the GOME-2 satellite instrument, Proceedings of the 2008 second workshop on USE of Remote Sensing Techniques for Monitoring Volcanoes and Seismogenic Areas Naples, Italy, 2008,

Rodgers, C. D.: Inverse Methods for Atmospheric Sounding, Series on Atmospheric Oceanic and Planetary Physics, World Scientific Publishing, Singapore, 2000.

Rose, W. I., Delene, D. J., Schneider, D. J., Bluth, G. J. S., Krueger, A. J., Sprod, I., McKee, C., Davies, H. L., and Ernst, G. G. J.: Ice in the 1994 Rabaul eruption cloud: implications for volcano hazard and atmospheric effects, Nature, 375, 477-479, 1995.
Sigmundsson, F., Hreinsdottir, S., Hooper, A., Arnadottir, T., Pedersen, R., Roberts, M. J., Oskarsson, N., Auriac, A., Decriem, J., Einarsson, P., Geirsson, H., Hensch, M., Ofeigsson, B. G., Sturkell, E., Sveinbjornsson, H., and Feigl, K. L.: Intrusion triggering of the 2010 Eyjafjallajokull explosive eruption, Nature, 468, 426-430, http://www.nature.com/nature/journal/v468/ n7322/abs/nature09558.html\#supplementary-information, 2010.

Smithsonian Institution: Large explosions from the summit crater; ash plumes close airspace in Europe, Bulletin of the Global Volcanism Network, 33:04, 2010.

Stamnes, K. and Swanson, R. A.: A New Look at the Discrete Ordinate Method for Radiative Transfer Calculations in Anisotropically Scattering Atmospheres, J. Atmos. Sci., 38, 387-399, doi:10.1175/1520-0469(1981)038<0387:ANLATD>2.0.CO;2, 1981.

Stohl, A., Prata, A. J., Eckhardt, S., Clarisse, L., Durant, A., Henne, S., Kristiansen, N. I., Minikin, A., Schumann, U., Seibert, P., Stebel, K., Thomas, H. E., Thorsteinsson, T., Tørseth, K., and Weinzierl, B.: Determination of time- and height-resolved volcanic ash emissions and their use for quantitative ash dispersion modeling: the 2010 Eyjafjallajökull eruption, Atmos. Chem. Phys., 11, 4333-4351, doi:10.5194/acp-11-4333-2011, 2011.

Swadzba, L., Maciejny, A., Formanek, B., Liberski, P., Podolski, P., Mendala, B., Gabriel, H., and Poznanska, A.: Influence of coatings obtained by PVD on the properties of aircraft compressor blades, Surf. Coat. Technol., 78, 137-143, 1996.

Thomas, H. E., Watson, I. M., Carn, S. A., Prata, A. J., and Realmuto, V. J.: A comparison of AIRS, MODIS and OMI sulphur dioxide retrievals in volcanic clouds, Geomatics, Nat. Hazards Risk, in press, 2011.

Thomason, L. W. and Pitts, M. C.: CALIPSO observations of volcanic aerosol in the stratosphere, Proc. SPIE, 7153, doi:10.1117/12.804090, 2008.

Torres, O., Tanskanen, A., Veihelmann, B., Ahn, C., Braak, R., Bhartia, P. K., Veefkind, P., and Levelt, P.: Aerosols and surface UV products from Ozone Monitoring Instrument observations: An overview, J. Geophys. Res., 112, D24S47, doi:10.1029/2007jd008809, 2007.

Vaughan, M. A., Young, S. A., Winker, D. M., Powell, K. A., Omar, A. H., Liu, Z., Hu, Y., and Hostetler, C. A.: Fully automated analysis of space-based lidar data: An overview of the CALIPSO retrieval algorithms and data products, Proc. SPIE Int. Soc. Opt. Eng., 5575, 16-30, 2004.

Wen, S. and Rose, W. I.: Retrieval of sizes and total masses of particles in volcanic clouds using AVHRR bands 4 and 5, J. Geophys. Res., 99, 5421-5431, doi:10.1029/93jd03340, 1994.

Yang, K., Krotkov, N. A., Krueger, A. J., Carn, S. A., Bhartia, P. K., and Levelt, P. F.: Retrieval of large volcanic $\mathrm{SO}_{2}$ columns from the Aura Ozone Monitoring Instrument: Comparison and limitations, J. Geophys. Res., 112, D24S43, 10.1029/2007jd008825, 2007.

Yu, T., Rose, W. I., and Prata, A. J.: Atmospheric correction for satellite-based volcanic ash mapping and retrievals using "split window" IR data from GOES and AVHRR, J. Geophys. Res., 107, 4311, doi:10.1029/2001jd000706, 2002. 